\title{
Creating Meaningful Partnerships Between Communities and Environmental Health Researchers:
}

The Role of a Direct Action Community Organizing Agency

\section{Rachael De Souza, MPH, MN,}

A rehabilitation nurse, Tacoma, WA

Genevieve C. Aguilar, MPA-URP, and

Associate Professor and Director, Occupational Health Nursing Program, University of Washington School of Nursing, Seattle, WA

\author{
A. B. de Castro, PhD, MSN/MPH, RN \\ Port Campaign Director, Puget Sound Sage, Seattle, WA
}

\begin{abstract}
Community engagement is a necessary, although challenging, element of environmental health research in communities. To facilitate the engagement process, direct action community organizing agencies can be useful in bringing together communities and researchers. This article describes the preliminary activities that one direct action community organizing agency used in partnership with researchers to improve community engagement in the first 6 months of an environmental health study conducted in a major U.S. city. Activities included developing communication strategies, creating opportunities for researcher-community interaction, and sustaining project momentum. To conduct environmental research that is both scientifically rigorous and relevant to communities, collaborating partners had to develop professional skills and strategies outside of their areas of expertise.
\end{abstract}

Community-based environmental health research is powerful because it addresses population health disparities by identifying community problems (Brown, 1995; Bullard \& Johnson, 2000). The Environmental Protection Agency (EPA) challenges researchers to conduct "humanized science," in which research findings inform policy decisions and affected communities inform the research process (Payne-Sturges, 2011). Frameworks that support this type of science include community-based participatory research (CBPR), participatory action research, and community-academic collaboratives (Morello-Frosch, Pastor, Porras, \& Sadd, 2002). To create successful partnerships between researchers and communities suggested by these frameworks, environmental health researchers must engage with community partners and affected communities must be motivated to partici-pate in

(C) Copyright $\odot$ American Association of Occupational Health Nurses, Inc.

Address correspondence to A. B. de Castro, PhD, MSN/MPH, RN, Box 357263, University of Washington, Seattle, WA 98195. butchdec@uw.edu.

The authors have disclosed no potential conflicts of interest, financial or otherwise. 
research. "Community engagement" is a process by which researchers and community members plan and participate together in a research project.

The process of community engagement is often challenging. Researchers may not have the skills or experience to effectively engage communities. Community engagement, as described in the CBPR literature, requires understanding social and political structures and sharing power, ideas, and responsibilities (Minkler \& Wallerstein, 2003). However, few researchers have experience or training in these areas, making community engagement difficult for them. Additionally, communities may not express interest in conducting environmental health research. For example, as described in the environmental justice literature, communities facing environmental health disparities often face numerous other health and security threats that may seem more pressing to them (Farquhar \& Wing, 2003). These challenges must be overcome to produce meaningful environmental health research.

The values and technical skills of direct action community organizing agencies make such groups useful in linking scientific researchers and community members. Direct action community organizing agencies are groups specializing in mobilizing and sustaining community involvement for the duration of an issue campaign (Bobo, Kendall, \& Max, 1996). By design, they appreciate the complexities of identity, political will, and competing interests (Pilisuk, McAllister, \& Rothman, 1996) and share power, which allows them to effectively engage with community members. Direct action community organizing agencies also have concrete skills, such as developing issue awareness, planning effective neighborhood meetings, recruiting participants, and building relationships (Pilisuk et al., 1996). These skills and values make direct action community organizing agencies effective partners for researchers interested in engaging community members in their research.

\section{EXAMPLE OF COMMUNITY ENGAGEMENT PARTNERSHIP}

This article describes ways that a community organizing agency can facilitate community engagement, using an environmental health research project as an example. This research project focused on diesel exhaust exposure in two communities near major truck routes in and out of a major U.S. port city. The context of this research project includes a long history of environmental justice advocacy initiatives and partnerships involving diverse groups to address air pollution, including diesel exhaust emissions. The local EPA identified diesel exhaust emissions as a dominant cancer risk in the city. Also, the affected communities had some of the highest asthma hospitalization rates in the city.

Prompted by a community organizing agency, researchers became aware of and interested in monitoring diesel exhaust concentrations in the affected communities. A few challenges were identified during the planning phase of this project. First, researchers had no personal connection with community members and little experience with community partnerships. Second, although community members had identified air pollution as a concern in a survey conducted by two community organizing agencies, they did not necessarily prioritize trafficrelated air pollution as their most significant concern. Other commonly voiced themes in neighborhood meetings were crime, unemployment, and proximity to industrial waste sites. 
A community organizing agency served to bring researchers and the community together for this project. This not-for-profit agency focused on direct action organizing around economic justice issues in the region. It was not located in the local neighborhood nor did any of its staff members live in the two communities; therefore, it was not a community-representative organization as described in the CBPR literature (Minkler \& Wallerstein, 2003). The community organizing agency planned a 6-month effort to raise awareness about the research project and solicit the communities' input about where, when, and how diesel exhaust monitoring should take place. To achieve this goal, the community organizing agency worked with researchers to identify and implement a community engagement process consisting of four components: (1) developing a community communication plan, (2) reaching diverse community members, (3) creating opportunities for community input, and (4) producing meaningful deliverables for the community.

\section{Developing a Community Communication Plan}

To create a communication strategy, the community organizing agency used a public communication development tool to develop high-impact communication with the community. Key first steps were problem definition, goal setting, and key stakeholder identification. Clearly defining the problem - both as a broad, systemic problem and as a narrower, actionable issue - acknowledged its complexity and provided a basis to create a solution. Goal setting was also essential because the goals of researchers and community members are rarely identical (Norris et al., 2007; Srinivasan \& Collman, 2005). Formulating a communication plan before starting a project avoids confusion and misunderstandings between the researchers and the community. Identifying stakeholder groups ensured inclusion and representation of multiple community interests. Also, identifying stakeholders' values before planning engagement activities allows these values to be respected and leveraged during engagement (Bobo et al., 1996). Furthermore, thoughtful characterization of each group's enabling and limiting socioecological factors, such as family structure and social class, as well as core values helped to plan effective outreach activities later.

After these initial steps, organizers created a carefully worded theme that they used to broadly promote the specific research issue. Carefully crafting an impactful message avoids "message fatigue," or the disinterest of communities that have repeatedly heard different versions of their environmental health problems and no longer care or understand (Thomas, Smith, \& Turcotte, 2009). Crafting the wording of a health message requires understanding the scope of the problem, the proposed intervention possibilities, and the community's capacity to understand (Kreuter, Lukwago, Bucholtz, Clark, \& Sanders-Thompson, 2003; Yancura, 2010). For this project, the community organizing agency proposed numerous message options, which were carefully considered with the researchers before making a final selection. Some, such as "Family First, Diesel Last" and "Easy Actions = Powerful Outcomes," appealed to many stakeholders' values, time constraints, and need for positive change. Other messages were less impactful. For example, "Protect Your Family's Health, Discover Diesel Sources" appealed to family needs, but imprecisely suggested that the main focus of the project was to identify diesel sources rather than air pollution concentrations. The group ultimately settled on "Build Knowledge; Easy Actions; Powerful Clean Air 
Outcomes" as the central message of the project. Carefully planned communication prevented confusion while promoting excitement about the project in the community.

\section{Reaching Diverse Community Members}

Once the message was crafted, it was distributed throughout the community to encourage community participation. Neighborhood-level community organizing has its roots in "building face-to-face relationships in specific local places" (Stoecker, 2002, p. 146). This commonly entails walking the streets, knocking on doors, and conversing with residents, inviting their involvement. Despite the growth of other methods of outreach, such as virtual organizing on the Internet, door-to-door outreach is still considered a powerful way to engage community members in a particular issue. Recruitment of community members is the essential task of community engagement and a primary skill of community organizing agencies (Bobo et al., 1996).

The community organizing agency in this project devised an extensive community outreach campaign built on doorstep encounters. The agency used census data to create doorknocking routes that prioritized outreach to community members who had expressed interest in the environmental issue previously and residents of diverse backgrounds, including both home owners and renters and individuals of different ethnicities. The agency hired a team of multi-lingual workers to ensure outreach to diverse residents. Volunteers and agency staff knocked on doors during evenings and weekends - times when residents would most likely be at home. By the end of the process, nearly 1,000 conversations had been initiated, including almost all community households. The community organizing agency also made presentations at local groups' meetings, such as neighborhood and merchant associations, acknowledging the need for direct, proactive communication with community and business leaders. The agency also provided outreach to local business places and at community gatherings, such as sporting events, meal programs, and meetings, to inform residents who may spend significant time working and playing, but not necessarily living, in the communities. The planning and time required to complete door-to-door outreach were substantial and demanded significant human resources, flexibility, experience, and a positive attitude among door-knockers.

The community organizing agency's door-knocking efforts succeeded in raising awareness about the project, learning about residents' environmental health concerns, and attracting residents to attend further planning meetings. As the weeks progressed, more individuals who were contacted expressed recognition of the main theme, indicating that knowledge about the project was spreading throughout the communities. These individual interactions also resulted in rich data that informed the project. For example, a substantial number of community members mentioned that they were very concerned about the hazards of jet fuel associated with nearby airport traffic. This was the first time significant concerns about jet fuel had been communicated directly to these researchers, despite previous reports from community activists to government agencies.

One stakeholder group the community organizing agency did not reach out to in the initial community engagement phase was the port, an important nearby industry with potential interest in this research effort. Like all stakeholders, inclusion of the port authorities would 
have added richness and meaning to the research effort. Later attempts by researchers and organizers to engage with the port in diesel exhaust monitoring efforts were challenging, perhaps partially because the port authorities were not principally included in earlier planning efforts. Given their knowledge of and relationships with industrial sectors, occupational health nurses working for industry might be direct points of contact in communicating with companies and businesses to ensure more complete community collaboration.

\section{Creating Opportunities for Community Input}

Large group meetings are common planning forums for community-level interventions because they encourage sharing information, developing ideas, and building consensus in less time than it takes to have numerous one-on-one encounters (Bobo et al., 1996; Fontana \& Frey, 1998). Gathering residents together can also build campaign momentum and earn media attention (Moyer, MacAllister, Finley, \& Soifer, 2001). In this project, the community organizing agency arranged community meetings to present basic scientific information on diesel exhaust and its health outcomes, as well as discuss monitoring and data presentation options.

The community organizing agency worked closely with researchers to ensure that scientific information was presented in an accessible and appropriate way. An example of this translational process came when attempting to convey the complex composition of diesel exhaust, as an explanation of why monitoring can be challenging. Researchers searched for a visual tool that was sophisticated enough to convey this concept yet straightforward enough for the audience to understand. The community organizers suggested passing around a large bottle of multicolored, mixed up jelly beans to represent the various components of diesel exhaust. This visual allowed researchers to explain the composition of diesel exhaust in an accessible way without oversimplifying a complex concept.

The community organizing agency and researchers worked together to ensure that community input was incorporated into monitoring methods and the presentation of results. For example, community members were asked where and when diesel exhaust should be measured because they had special insight into where trucks idled in the morning and what time garbage trucks passed. However, some homeowners worried that if a site near their property was identified as a "diesel hotspot," their property value would fall and they would be unfairly targeted. Anticipating this, the community organizing agency and researchers worked together to find an appropriate way to present the final data. It was decided that the final reports would not specify exact monitoring sites, but rather present the data as gradient maps.

In addition to sharing information about the project, the community organizers planned community meetings to address broad issues. Most notably, community meetings began with a health fair focusing on diesel exhaust-related health concerns. The community organizing agency solicited the assistance of community health organizations to provide activities, information, and resources for children and adults. The health fairs addressed the project's aims by teaching individuals about environmental health and motivating them to take action. They also provided an engaging entry activity, flexibility for meeting start time 
to accommodate latecomers, and diversion for children during formal presentations. Meetings were also scheduled at times and locations convenient for residents and food, childcare, and interpreter services were provided.

Despite these efforts, attendees were not representative of the neighborhoods' diversity. Alternative participation opportunities were needed to reach all pockets of community members. In response, the community organizing agency conducted interviews in residents' homes and organized small gatherings for specific population groups. This required significantly more time, communication, and coordination of volunteers than initially planned. Organizers understand that community organizing "is a lifetime occupation requiring lifetime commitments," recurrent long work days, and at times personal sacrifice (Bobo et al., 1996, pp. 240, 243). For those reasons, effective community organizing agencies incorporate support systems into their structure so they can push through demanding times. For this project, the community organizing agency budgeted for frequent team debriefing sessions and volunteer dinners to provide support during the long weeks.

\section{Producing Meaningful Deliverables for the Community}

A common obstacle in community organizing is the long-term commitment required. The time and struggle needed to create social change can discourage community residents and organizers in the present (Moyer, MacAllister, Finley, \& Soifer, 2001). Similarly, the scale and seeming slowness of an environmental health research project can be frustrating to community members who are facing health impacts each day. This sense of failure can undermine a gradually building community engagement effort, unless countered with recognition of real, intermediate successes (Bobo et al., 1996).

Community organizing agencies understand the value of producing some kind of meaningful deliverables celebrating small-scale, incremental achievements. The type and timing of deliverables are strategic considerations. For example, in this project's community engagement process, community members needed to be aware early in the project of successes achieved by other neighborhoods facing similar problems. Case studies of environmental health research projects from other cities were developed to illustrate approaches to mitigate diesel exhaust-related concerns. It was also important to convey immediately applicable, short-term solutions. To achieve this, the community organizing agency connected residents with free services to evaluate home environmental health hazards and offer remediation advice. Recognizing incremental success infused this longterm project with needed enthusiasm and added value to the project for participating community members. A review of community-based environmental justice research has shown that participants typically define success not by achieved final long-term goals, but rather by smaller successes along the way (Lynn, 2000).

\section{DISCUSSION}

This article has described the ways in which direct action community organizing agencies can bring researchers and community members together. The outreach phase of the environmental health project highlighted in this article exemplifies how community organizers plan effective communication, outreach, and gatherings and sustain project 
momentum. At the same time, partnering with community organizing agencies to conduct environmental health research poses challenges.

The communication styles of community organizers and researchers can be very different. Researchers are conventionally trained to be objective and rely on the weight of evidence when drawing conclusions. Community organizers are trained to simplify complex issues into actionable items that promote and inspire change. When these different orientations inform the same engagement process, researchers may be concerned about misrepresentation and oversimplification of facts and community organizers may be frustrated by caveated statements. Two examples from this project illustrate this point. First, when arranging the initial health fair, community organizers wanted to "raise an alarm" about a causative relationship between diesel exhaust exposure and asthma onset. However, scientists explained to the organizers that little scientific evidence supports the causal relationship between diesel exhaust exposure and asthma onset. A message was then crafted to highlight diesel exhaust's research-supported role in asthma exacerbations. Although "exacerbation" does not hold the same weight as "cause" in the public's mind, it was a truth on which researchers and organizers could agree. Second, a similar instance arose when, in planning the community meeting presentation, researchers wanted to display a map of the United States showing traffic-related pollution in various cities. Some cities on this map showed higher annual averages than the metropolitan area in this study. Community organizers were concerned that this map would disengage residents from the project, because it suggested that air pollution was less of a problem in their area. However, scientists felt it was appropriate to give context to, and not overstate, the problem. Researchers and organizers agreed to pair this slide with information about local asthma hospitalization rates. This approach showed that although between-city comparisons of diesel exhaust levels might minimize the problem, within-city comparisons of health outcomes indicated that diesel exhaust was a real concern for these residents.

Traditionally, direct action community organizing agencies promote social justice. The community organizing agency must be careful to facilitate community voices, rather than push its own advocacy agenda, if any. In this project, the community organizing agency also managed a campaign to improve port working conditions, which could have become a conflict of interest in a diesel exhaust-related research project. As such, the community organizing agency continually made efforts to keep outreach materials free of a political agenda. For example, when asking community members what types of diesel sources most concerned them, the community organizing agency randomly rotated the source options between garbage trucks, trains, buses, port trucks, and generators on survey forms. This ensured that bias against port-related sources was not introduced. Researchers also crafted concise questions that were not leading in any way. Although organizers, and researchers for that matter, may have felt strongly that this campaign or issue was of primary importance, communities may have felt otherwise. Allowing the community to identify its own needs and select its own priorities is the crux of community-based work. As explained by Pilisuk et al. (1996), when community organizing agencies define problems for communities, they disempower communities and risk missing crucial information: 
The failure of some grassroots efforts can be attributed sometimes to their takeover by professional helpers.... While expert knowledge is necessary, the need for grassroots organizing to define the problem seems obvious. (pp. 29-30)

Without conscientious self-control and dedication to its mission of community empowerment, a community organizing agency can become an "outside expert," prone to assuming it knows what is best for the community (e.g., what questions should be asked, how they should be investigated, what the possible solutions are). These pitfalls are similar to those faced by the traditional researcher working without community engagement efforts in community settings. Sharing power and responsibility with the community is complex, although it is the ideal way to conduct meaningful community-based research.

A few examples of researchers openly partnering with advocacy organizations to conduct scientific research have been published in the literature. Advocates and researchers who partner encounter struggles and successes similar to those described in this article (Baralt \& McCormick, 2010). Experiences reported here and elsewhere suggest that community organizing and advocacy agencies have much to contribute to community-based research. Environmental health researchers (particularly nurse researchers) can potentially benefit from partnering with these organizations, as the researchers will gain better understanding of the communities in which they conduct research and also secure the engagement of community members who are willing to participate in the study.

According to Bullard and Johnson (2000), communities facing environmental health threats must call for and leverage meaningful environmental health research to create positive change. Environmental health researchers interested in meaningful contributions to health improvement efforts for community members can support this process by conducting community-based research with strong community engagement. Environmental health researchers have technical and analytical skills that make them invaluable partners. Community members have knowledge and perspective about their environmental health concerns that are not available elsewhere, giving meaning to the research. Direct action community organizers contribute special expertise that explicitly confers power to community voices, facilitating communication between researchers and community members and promoting the quality and sustainability of rigorous community-based scientific research.

\section{IMPLICATIONS FOR PRACTICE}

True community engagement in a research project benefits the local community, state and federal policy makers, and the researchers. By engaging in problems that a disadvantaged community wants solved, the community gains the ability to advocate for itself, policy makers have stronger grounds on which to base decisions, and researchers apply their skills toward building a more just society.

To conduct meaningful research in communities, researchers must first assess their ability to engage the target community. Community engagement is a complex, dynamic process; learning to do it is not necessarily a part of a research scientist's training. Partnering with a direct action community organizing agency, as described in this article, or including 
community engagement training in a researcher's core academic training can improve the chances for successful research projects in communities.

\section{Acknowledgments}

This publication was made possible by Grant 2T42OH008433-06 from the National Institute for Occupational Safety and Health (NIOSH), Grant 5KL2RR025015 from the National Center for Research Resources (NCRR), a component of the National Institutes of Health (NIH), and Grant 243259 from The Kresge Foundation. Its contents are solely the responsibility of the authors and do not necessarily represent the official view of NIOSH, NCRR, NIH, or The Kresge Foundation.

The authors thank all of the volunteers and community members who participated in the efforts described.

\section{REFERENCES}

Baralt LB, McCormick S. A review of advocate-scientist collaboration in federally funded environmental breast cancer research centers. Environmental Health Perspectives. 2010; 118(12): 1668-1675. [PubMed: 20621848]

Bobo, K.; Kendall, J.; Max, S. Organizing for social change: A manual for activists in the 1990s. Santa Ana, CA: Seven Locks Press; 1996.

Brown P. Race, class, and environmental health: A review and systematization of the literature. Environmental Research. 1995; 69:15-30. [PubMed: 7588491]

Bullard RD, Johnson GS. Environmentalism and public policy. Environmental justice: Grassroots activism and its impact on public policy decision making. Journal of Social Issues. 2000; 56(3): $555-578$.

Farquhar, SA.; Wing, S. Methodological and ethical considerations in community-driven environmental justice research. In: Minkler, M.; Wallerstein, N., editors. Community based participatory research for health. San Francisco, CA: Jossey-Bass; 2003. p. 221-241.

Fontana, A.; Frey, JH. Interviewing: The art of science. In: Denzin, NK.; Lincoln, YS., editors. Collecting and interpreting qualitative materials. Thousand Oaks, CA: Sage; 1998. p. 47-78.

Kreuter MW, Lukwago SN, Bucholtz DC, Clark EM, Sanders-Thompson V. Achieving cultural appropriateness in health promotion programs: Targeted and tailored approaches. Health Education and Behavior. 2003; 30(2):133-146. [PubMed: 12693519]

Lynn FM. Community-scientist collaboration in environmental research. American Behavioral Scientist. 2000; 44(4):649-663.

Minkler, M.; Wallerstein, N. Introduction to community based participatory research. In: Minkler, M.; Wallerstein, N., editors. Community based participatory research for health. San Francisco, CA: Jossey-Bass; 2003. p. 3-26.

Morello-Frosch R, Pastor M Jr, Porras C, Sadd J. Environmental justice and regional inequality in southern California: Implications for future research. Environmental Health Perspectives. 2002; 110(Suppl. 2):149-154. [PubMed: 11929723]

Moyer, B.; MacAllister, J.; Finley, ML.; Soifer, S. Doing democracy. Gabriola Island, British Columbia: New Society Publishers; 2001.

Norris KC, Brusuelas R, Jones L, Miranda J, Duru OK, Mangione CM. Partnering with communitybased organizations: An academic institution's evolving perspective. Ethnicity and Disease. 2007; 17:S1-S9. [PubMed: 17598309]

Payne-Sturges D. Humanizing science at the US Environmental Protection Agency. American Journal of Public Health. 2011; 101(Suppl. 1):S8-S12. [PubMed: 22028453]

Pilisuk M, McAllister J, Rothman J. Coming together for action: The challenge of contemporary grassroots community organizing. Journal of Social Issues. 1996; 52(1):15-37.

Srinivasan S, Collman GW. Evolving partnerships in community. Environmental Health Perspectives. 2005; 113(12):1814-1816. [PubMed: 16330370]

Stoecker R. Cyberspace vs. face-to-face: Community organizing in the new millennium. Perspectives on Global Development and Technology. 2002; 1(2):143-164. 
Thomas GD, Smith SW, Turcotte JA. Using public relations strategies to prompt populations at risk to seek health information: The Hanford Community Health Project. Health Promotion Practice. 2009; 10(1):92-101. [PubMed: 18353906]

Yancura LA. Delivering culturally sensitive health messages: The process of adapting brochures for grandparents raising grandchildren in Hawai'i. Health Promotion Practice. 2010; 11(3):400-407. [PubMed: 19129435] 


\section{Applying Research to Practice}

Community engagement is a necessary, although challenging, part of community-based environmental health research. Community engagement is especially challenging if researchers are not trained in community relations, community organizers do not have experience collaborating on a scientific study, or environmental health is only one of community members' many concerns. Direct action community organizing agencies specialize in community engagement activities, including developing communication strategies, reaching diverse groups, creating opportunities for meaningful interaction, and providing for sustainability. Balancing the advocacy mission of community organizers with researchers' commitment to scientific objectivity can be challenging. Recognizing the strengths and values of both contributes to healthy partnerships. 